Research Article

\title{
Utilising Smartphone Light Sensors to Measure Egg White Ovalbumin Concentration in Eggs Collected from Yinchuan City, China
}

\author{
Linlin Liu $(\mathbb{D})$ and Hualin Bi $(\mathbb{C}$ \\ College of Chemistry, Chemical Engineering and Materials Science, Shandong Normal University, Jinan, Shandong, China \\ Correspondence should be addressed to Hualin Bi; bihualin@sdnu.edu.cn
}

Received 18 March 2020; Revised 16 June 2020; Accepted 29 June 2020; Published 21 July 2020

Academic Editor: Massimiliano F. Peana

Copyright (c) 2020 Linlin Liu and Hualin Bi. This is an open access article distributed under the Creative Commons Attribution License, which permits unrestricted use, distribution, and reproduction in any medium, provided the original work is properly cited.

\begin{abstract}
Cost-effective, portable, and rapid smartphone sensors will play a critical role in bringing chemical detection technologies from central laboratories to simple laboratories, such as those of schools in less-developed area. In this work, we study whether eggs in Yinchuan have a higher concentration of ovalbumin than that in ordinary eggs. We summarise previous research on sensors built inside smartphones, as well as some developments in the current literature, and develop a simple experimental procedure that utilises the light sensor of a smartphone to analyse light intensity and thereby determine the ovalbumin content of egg white cheaply and quickly. Most of the materials required for conducting this experiment can be easily found in simple school laboratories, and it allows solution concentrations to be quickly assessed by high school students in the data collection and analysis phase. Indeed, the data collected using smartphone light sensors were similar to those obtained using a spectrometer. It was concluded that egg white ovalbumin concentration in eggs collected from Yinchuan is higher than that in ordinary eggs.
\end{abstract}

\section{Introduction}

Due to continuous developments in science and technology, smartphones have become rich in features, while their cost has gradually reduced; at present, smartphones that are fully equipped with a variety of sensors are available for under 150 U.S. dollars. Compared to costly and bulky digital information system (DIS), which costs around 1,500 U.S. dollars for a kit, smartphones are a cheaper and more portable alternative that is more suitable for laypeople, researchers conducting field survey, and students conducting scientific experiments in resource-limited areas. While chemists strive to improve chemical technologies, they should consider how this technology can be effectively used by students and laymen who want to understand chemistry. Smartphones could see more uses in the research field of chemistry if they are utilised for more practical applications.

Selenium has been proposed to have a role in protein synthesis. The local soil of Yinchuan is rich in selenium. Thus, it is ideal to check whether the eggs in Yinchuan have a higher concentration of ovalbumin than that in ordinary eggs. Yinchuan is a less-developed area in China, and the development of more selective and cost-effective equipment for use in daily chemical experiments is highly desirable. Many schools in less-developed areas are not equipped with traditional sensor devices, but almost everyone has a smartphone that they can use to explore the world around them. This also includes conducting chemical experiments anywhere and anytime. For these reasons, a growing number of researchers are investigating mobile resources. Researchers from many countries have engaged themselves in this field, including those from the United States, Germany, South Africa, Spain, Scotland, Uruguay, Turkey, Australia, and China [1-4]. By the end of January 2020, there have been nearly 6,000 research articles published related to smartphone sensor experiments, which is regarded as a prevailing field around the world. Common methods of using smartphones for scientific inquiry focus on two aspects: the manifest functions of smartphones 
and the sensors inside smartphones. This report describes an experiment to determine the egg white ovalbumin concentration in eggs collected from Yinchuan, using the built-in light sensor of a smartphone.

The range of experiments that can be carried out using smartphone sensors is extremely wide. Current research has covered many fields including biochemistry, optics, acoustics, and thermodynamics. For example, several researchers have investigated free-falling through mobile phones using a variety of sensors, including accelerometers, air pressure sensors, and GPS [5-7]. Smartphone sensors can also be used as optical microscopes $[8,9]$, with many reports describing how smartphones can be used to design simple and inexpensive photometers for daily use [10-12]. In 2016, Thomas put forward a method of using a smartphone camera and related software in the spectrophotometric analysis of $\mathrm{CuSO}_{4}$ solution concentration [13]. Khalili integrated a generic holographic sensor platform and a smartphone-based colour quantification algorithm in order to standardise and improve the determination of the concentration of analytes of interest [14]. These experiments further simplified the process of creating simple photometers from smartphones and cameras, allowing photometry to be conducted in every high school laboratory, but they ignored the effects of stray light and low-concentration solutions [15]. Furthermore, the analyte concentration only can be determined from colour change. In order to measure ovalbumin concentration in egg white, experiments to measure the concentration in low-concentration colourless solutions should be designed. With this in mind, we earlier designed the salting-out method-based quantitative experiment [16-19]. Traditionally, ovalbumin concentration is measured using an ultraviolet and visible spectrophotometer; however, certain citizen science squares and high schools cannot afford expensive visible spectrophotometers for communities and groups of students. To overcome this difficulty, a new saltingout-based method for ovalbumin extraction from egg white and determination of ovalbumin concentration was developed in this study. It is emphasised that the ovalbumin concentration of the egg white can be measured using the built-in light sensor found in a cheap smartphone.

This experiment focuses on utilising the built-in light sensors of smartphones to measure the ovalbumin concentration of egg white and involves the following steps:

(1) Preparing a calibration curve using saline solutions containing bovine serum albumin (BSA)

(2) Using ammonium sulfate salting-out to extract ovalbumin from egg white

(3) Verifying the presence of ovalbumin in the solution chemically, using the Coomassie brilliant blue (CBB) test

(4) Determining ovalbumin concentration using a smartphone

\section{Materials and Methods}

The equipment required for this experiment included one $50 \mathrm{~mL}$ volumetric flask, two quartz cuvettes $(12.5 \mathrm{~mm} \times$
$12.5 \mathrm{~mm} \times 45.2 \mathrm{~mm}$; AICE, Hangzhou, China), four $150 \mathrm{~mL}$ beakers, one $750 \mathrm{~mL}$ beaker, two $100 \mathrm{~mL}$ volumetric cylinders, ten test tubes, three stirring rods, four $5 \mathrm{~mL}$ syringes, four $10 \mathrm{~mL}$ centrifuge tubes, one centrifuge, and one smartphone (in this case, a Samsung Galaxy S4, Android 4.0 was used). A smartphone application capable of determining the average intensity of ultraviolet light passing through the solution in real time is also required (for use as a light detector). The spectrophotometer used in traditional experiment was Varian CARY 5000 UV-VIS spectrophotometer in the range of $200-1000 \mathrm{~nm}$. Details for setting up the smartphone-based instrument are provided below. The eggs selected in this study were purchased from 20 different markets in Yinchuan, and they were all common local eggs, not those produced by rare breeds.

2.1. Developing the Instrument. To facilitate the measurement of the ultraviolet flashlight intensity and to avoid interference from other light sources, a lighttight plastic box was used to construct a cuvette holder in which the cuvette was set. Two holes were cut as indicated in Figures 1(a) and 1(b). The hole's radius we made for cuvette holders was $0.2 \mathrm{~mm}$ and no larger than the flashlight bulb. The height from the bottom edge of the cuvette was $1 \mathrm{~cm}$. The lighttight plastic board was then folded to make a box, as shown in Figure 1(a), ensuring that holes A and B faced each other. Holes A and B on the back of the box is shown in Figure 1(b). Hole B was closely attached to the light sensor. The cuvette was placed in the cuvette holder.

The cuvette holder was fixed on the smartphone (Samsung Galaxy S4), and the sensor was attached to one of the holes on the holder (Figure 2(a)). The box was arranged such that light penetrating through the cuvette could be detected by the smartphone (Figure 2(b)). A $595 \mathrm{~nm}$ ultraviolet flashlight (Blnmax, Ningbo, China) was used as the light source. A diagram of the complete apparatus is shown in Figure 2(c). The built-in sensor required no user installation.

The smartphone application "Luxmeter with graph" (or a similar photometer application) was downloaded onto the android smartphone to measure light intensity. This free Luxmeter can be used for measurement for any purpose-for comparison, for simple experiments, or just for fun. This is a free version and has no limitations. Moreover, improvements, new features, and users' requests are always implemented on the free version. This study uses Luxmeter with graph as an example. More information regarding this application can be found at the following link: https://www. amazon.com/dp/b00mdub0ze/. In case the smartphone being used is an iPhone, many similar alternative photometer applications can be installed on the iOS smartphones. More detailed information and helpful tips may be found in the Supplementary Materials.

\subsection{Sample Preparation}

2.2.1. CBB Reagent. CBB G250 (100 mg) (Analytical Reagent, Vorradex, Nanjing, China) was dissolved in $50 \mathrm{~mL}$ 


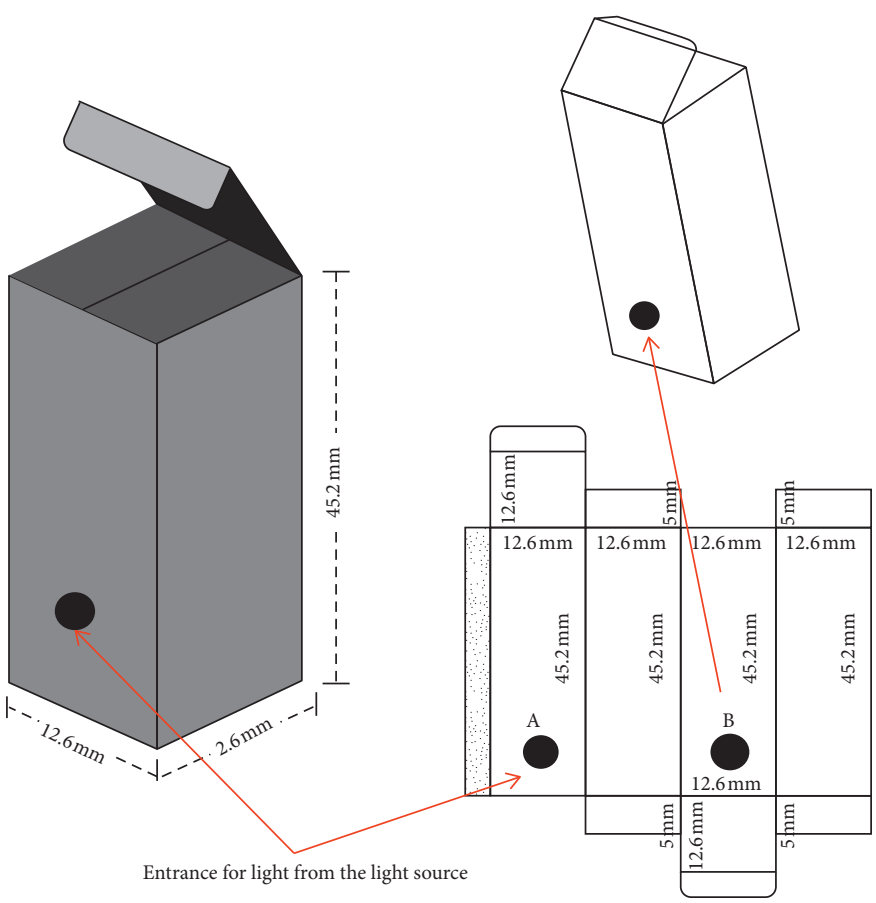

(a)
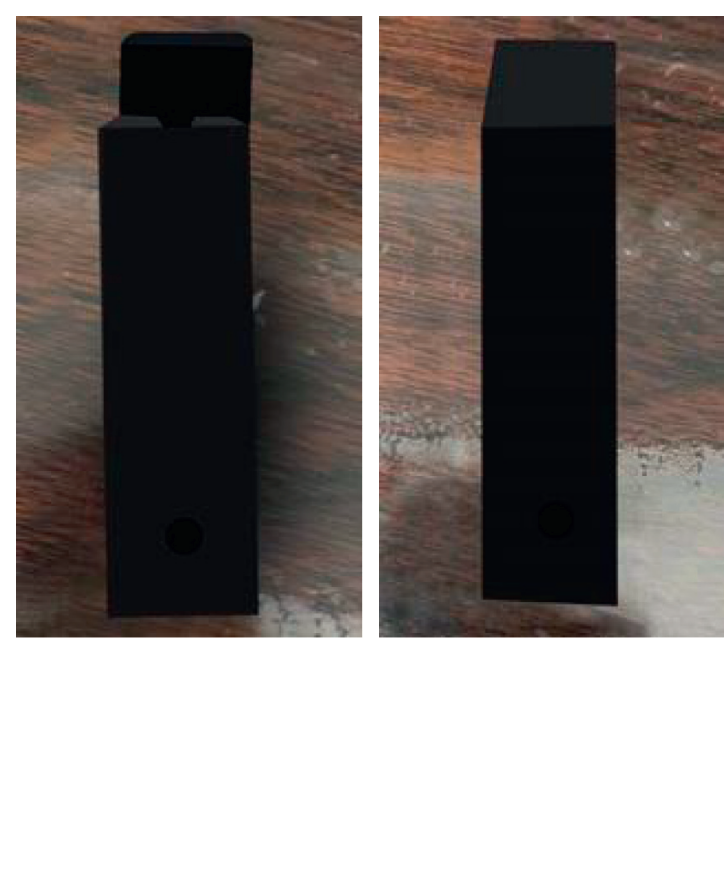

(b)

Figure 1: Schematic (a) and photo (b) of homemade cuvette holder.

95\% ethanol; $100 \mathrm{~mL} 85 \%$ phosphoric acid was added to this and diluted to $1000 \mathrm{~mL}$ with distilled water and then filtered. The CBB reagent can combine with protein $\mathrm{NH}_{3}$ bond in acid medium to cause the solution colour turn blue. Moreover, staining the solutions with $\mathrm{CBB}$ allowed easy protein detection.

2.2.2. BSA Normal Saline Solution. Ten BSA samples (Analytical Reagent, Vorradex, Nanjing, China) of known concentrations were prepared by dissolving BSA in normal saline solution. The solutions were stained with CBB.

\subsubsection{Salting-Out Method and Extraction of Ovalbumin from} Egg White. The surface of the protein molecule contains charged groups, which have significant affinity for water molecules. Thus, in an aqueous solution, the protein forms a hydration membrane to increase the stability of the proteinwater solution. The membrane will be destroyed if a large amount of neutral salt is added to the protein solution, as this neutralizes the surface charge of the protein molecules [20]. The protein molecules then agglomerate and can be separated from the solution. The precipitate is crude ovalbumin, which should be measured.

This precipitate was then dissolved in normal saline solution, and the presence of the protein was confirmed using $\mathrm{CBB}$ staining. In this study, researchers used eggs collected from other cities as the control group, while students used local eggs as the experimental group. Researchers also measured the concentration of BSA by drawing a calibration curve.

\subsection{Utilising Smartphone Light Sensors to Measure Samples}

2.3.1. Preparing Calibration Curves. In this spectrometry experiment, transparent solutions were irradiated with UV light, and the portion of light that passes through the solution was measured (Figure 3).

Equations (1) and (2) are known as Lambert-Beer's law and are useful for calculating sample concentrations [15]:

$$
A=\varepsilon l c .
$$

Here, $A$ is the absorbance of the solution, $\varepsilon$ is the molar attenuation coefficient, which is a constant determined solely by the wavelength used for analysis, $l$ is the cell path length, and $c$ is the solution concentration. Absorbance is directly proportional to the solution concentration when $\varepsilon$ and $l$ remain constant $[15,21]$ :

$$
A=-\lg \frac{I}{I_{0}} .
$$

Here, $I$ is the intensity of light transmitted through the sample and $I_{0}$ is the intensity of light transmitted through a blank sample. Thus, the solution concentration $(c)$ can be obtained by determining $I$. It is assumed that the incident light is a parallel monochromatic light that passes through the solution vertically.

The intensity of light transmitted through samples of BSA-normal saline solution and normal saline solution was measured, and a calibration curve of the intensity of UV light penetrating BSA samples of different concentrations was prepared. Equations (1) and (2) were then used to convert this to a calibration curve of absorbance vs BSA concentration. 


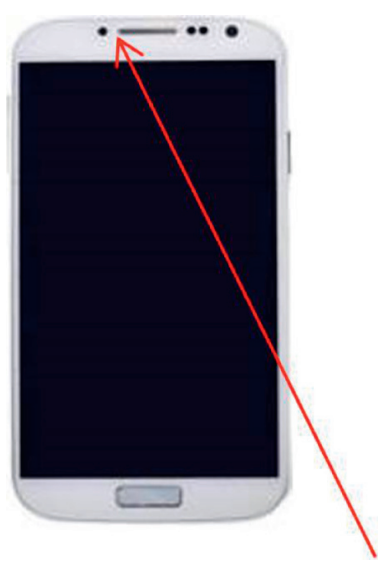

Light sensor (a)

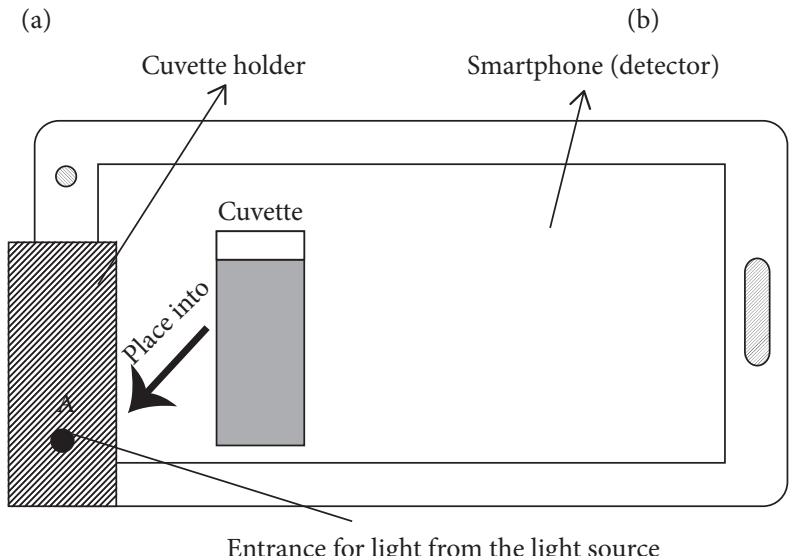

(c)

(b)

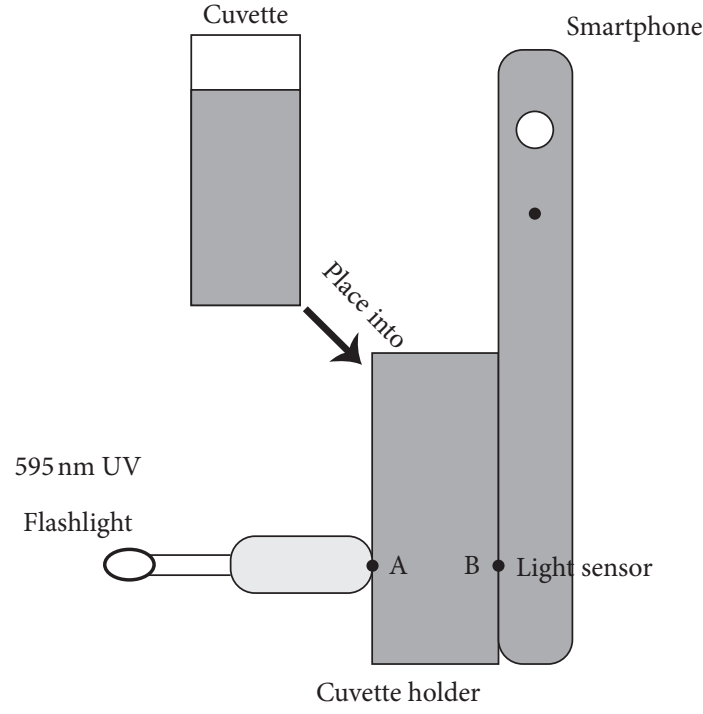

Figure 2: Experimental setup. (a) The location of the smartphone's sensors. (b) Side view of the instrument. (c) Front view of the instrument.

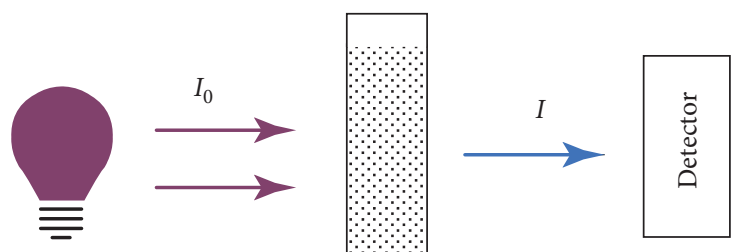

FIGURE 3: UV light produced by a $595 \mathrm{~nm}$ UV flashlight passes through a transparent solution. The amount of light transmitted through the solution is detected by a smartphone.

2.3.2. Utilising Smartph One Light Sensor to Measure Concentration of Ovalbumin in Egg White. The intensity of light transmitted through normal saline solutions containing the precipitate was measured using the experimental setup. The solution concentration was determined by comparing this value to the calibration curve.

\section{Results and Discussion}

3.1. Drawing Protein Calibration Curve Using BSA-Normal Saline Solutions. Solutions of BSA in normal saline with ten known concentrations $(0.05 \mathrm{~g} / \mathrm{L}, 0.10 \mathrm{~g} / \mathrm{L}, 0.15 \mathrm{~g} / \mathrm{L}, 0.20 \mathrm{~g} / \mathrm{L}$, $0.25 \mathrm{~g} / \mathrm{L}, 0.30 \mathrm{~g} / \mathrm{L}, 0.35 \mathrm{~g} / \mathrm{L}, 0.40 \mathrm{~g} / \mathrm{L}, 0.45 \mathrm{~g} / \mathrm{L}$, and $0.50 \mathrm{~g} / \mathrm{L}$ ) were prepared. CBB $(5 \mathrm{~mL})$ was added into BSA-normal saline solutions. The protein concentration can be measured easily by staining with CBB. Before the experiment, the sensor had been wiped with the computer detergent containing volatile hydrocarbon detergent, antisedimentation agent, surface cleaner detergent, and antistatic agent. The light intensity analyser application on the smartphone was opened. A cuvette filled with normal saline solution and CBB (i.e., a blank) was placed in the cuvette holder, and the UV 
flashlight was operated such that UV light could pass through the holes into the light sensor of the smartphone, and the intensity of light passing through the blank sample $\left(I_{0}\right)$ could be recorded. The intensities of UV light that penetrated through the solutions with known concentrations $\left(I_{1}-I_{10}\right)$ were then measured in a similar manner. The software interface is shown in Figure 4.

The application recorded the intensity of UV light penetrating through the blank solution $\left(I_{0}=331.2\right.$ lux $)$ and BSA sample $\left(I_{10}=254.4\right.$ lux $)$. Equation (2) yielded an absorbance of 0.115 for the BSA-normal saline solution $(0.50 \mathrm{~g} / \mathrm{L})$.

The intensities of light transmitted through the BSAnormal saline solutions and the reference sample were measured using the apparatus described above (Table 1), after which a curve of the UV light intensity penetrating through the BSA samples was prepared (Figure 5). This was then converted to a calibration curve of the absorbance of BSA-normal saline solutions by equation (2) (Table 2 and Figure 6).

\subsection{Using Ammonium Sulfate Salting-Out to Extract Oval-} bumin from Egg White and Verifying the Presence of Ovalbumin. The volume and mass of an egg white were measured using a volumetric cylinder and an analytical balance, respectively. The mass of the whole egg was determined at the beginning of the experiment. A small hole was then created at one end of the egg to transfer the egg white into a volumetric cylinder. The mass of the eggshell and yolk was then determined. The difference between the mass of the whole egg and that of the shell and yolk was the mass of the egg white (denoted by $m$ ).

In order to extract ovalbumin from the egg white, raw egg white and normal saline (Vorradex, Nanjing, China) were combined in a $1: 1$ volume ratio in a $150 \mathrm{~mL}$ beaker (AICE, Hangzhou, China). The egg white and saline solution were mixed, and the mixture was allowed to stand for $10 \mathrm{~min}$. A same volume of saturated ammonium sulfate (60\%, Vorradex, Nanjing, China) was added into mixture, as saturated ammonium sulfate (60\%) can be used to separate ovalbumin from egg white [22]. Following this, the mixture was transferred into a centrifuge tube [23] and centrifuged at $3000 \mathrm{rpm}$ for $10 \mathrm{~min}$ (centrifuge, $220 \mathrm{~V}, 50 \mathrm{~Hz}, \operatorname{Max}$ Speed $=16600 \mathrm{rpm}$, AICE, Hangzhou, China). The supernatant was collected, and ammonium sulfate was continuously added into it until no additional ammonium sulfate could be dissolved. This mixture was allowed to stand for $10 \mathrm{~min}$ and then centrifuged at $3000 \mathrm{rpm}$ for $10 \mathrm{~min}$. The precipitate, which is crude ovalbumin, was collected. The

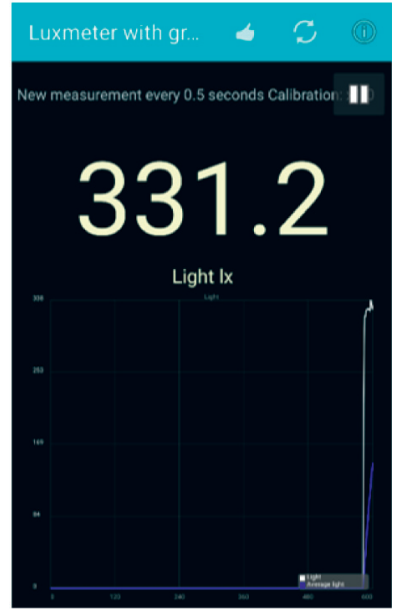

(a)

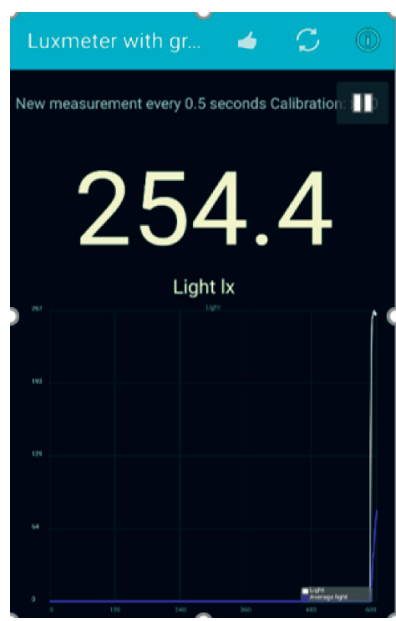

(b)
Figure 4: View of a blank sample (a) and a sample containing $0.5 \mathrm{~g} \cdot \mathrm{L}^{-1} \mathrm{BSA}$-normal saline solution (b) through the Luxmeter with graph application on a smartphone.

extracted crude ovalbumin was dissolved in normal saline to $0.7 \mathrm{~L}$ (denoted by $V$ ) to prevent the formation of protein dimers [24]. Finally, CBB ( $5 \mathrm{~mL})$ was added to this solution, causing the solution to turn blue, thereby confirming the presence of the protein (Figure 7). Moreover, staining the solutions with $\mathrm{CBB}$ allowed easy protein detection.

3.3. Determination of Ovalbumin Concentration. Briefly, $595 \mathrm{~nm}$ ultraviolet flashlight was turned on, and the smartphone's light intensity analyser application was opened. A cuvette filled with $2.5 \mathrm{~mL}$ of ovalbumin-normal saline solution was placed in the cuvette holder, the ultraviolet light passing through the solution was recorded, and the absorbance of each sample was determined using equation (2). Subsequently, absorbance values were converted into concentrations using the curve, and this process was repeated four times to give ten concentrations $\left(c_{1}, c_{2}, c_{3}\right.$, $c_{4}, c_{5}, c_{6}, c_{7}, c_{8}, c_{9}$, and $\left.c_{10}\right)$. The intensities of UV light penetrating through the sample are given in Table 3. Intensity was converted to absorbance by equation (2). Absorbance was converted to concentration by equation (1). The concentration values are also shown in Table 3 that are obtained from the five tests of an egg white with a mass of $57.1 \mathrm{~g}$.

The formula for calculating the ovalbumin mass fraction of the egg white is as follows [20, 25-27]:

$$
\begin{aligned}
\text { mass fraction }(W) & =\frac{\text { average ovalbumin concentration }(c) \times \text { volume }(\mathrm{V}) \times 100 \%}{\text { eggs mass }(m)} \\
W & =\frac{\left(c_{1}+c_{2}+\ldots+c_{n}\right) V \times 100 \%}{n m} .
\end{aligned}
$$


TABLE 1: Intensities of BSA-normal saline solutions measured by a smartphone.

\begin{tabular}{lc}
\hline $\begin{array}{l}\text { Concentration of BSA- } \\
\text { normal saline }(\mathrm{g} / \mathrm{L})\end{array}$ & $\begin{array}{c}\text { Intensity of UV light penetrating } \\
\text { through }\end{array}$ \\
\hline 0.05 & 324.4 \\
0.10 & 317.0 \\
0.15 & 310.5 \\
0.20 & 300.0 \\
0.25 & 289.8 \\
0.30 & 279.3 \\
0.35 & 274.8 \\
0.40 & 267.9 \\
0.45 & 260.7 \\
0.50 & 254.4 \\
\hline
\end{tabular}

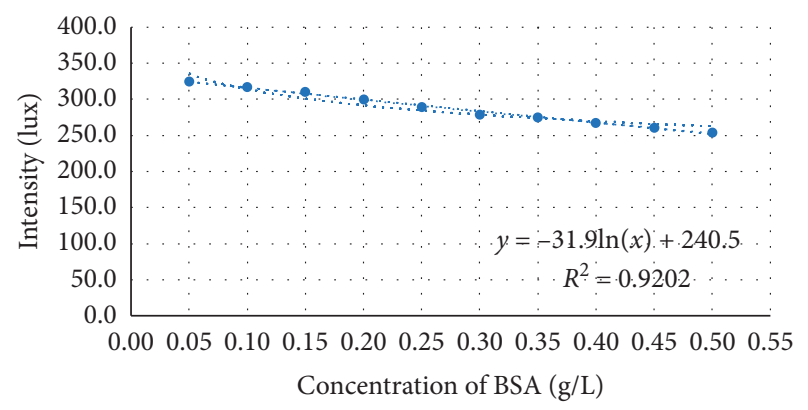

FIgURE 5: Calibration curve of UV intensity penetrating through known BSA samples.

TABLE 2: Absorbance of known BSA-normal saline solutions measured by a smartphone.

\begin{tabular}{lc}
\hline $\begin{array}{l}\text { Concentration of BSA-normal } \\
\text { saline }(\mathrm{g} / \mathrm{L})\end{array}$ & Absorbance (arbitrary units) \\
\hline 0.000 & 0.000 \\
0.050 & 0.009 \\
0.100 & 0.019 \\
0.150 & 0.028 \\
0.200 & 0.043 \\
0.250 & 0.058 \\
0.300 & 0.074 \\
0.350 & 0.081 \\
0.400 & 0.092 \\
0.450 & 0.104 \\
0.500 & 0.115 \\
\hline
\end{tabular}

Here, mass fraction is denoted by $W, m$ is the mass of the egg measured in $\mathrm{g}, V$ is the volume measured in $L$, and $c$ is the average ovalbumin concentration measured in $\mathrm{g} / \mathrm{L}$. The ovalbumin mass fraction determined using the data above and Equation (3) was $0.554 \%$.

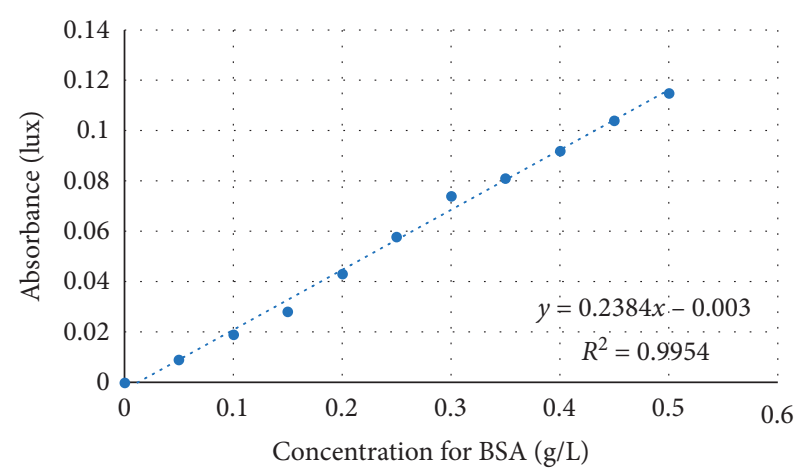

FIgURE 6: Calibration curve for absorbance of known BSA-normal saline solutions.

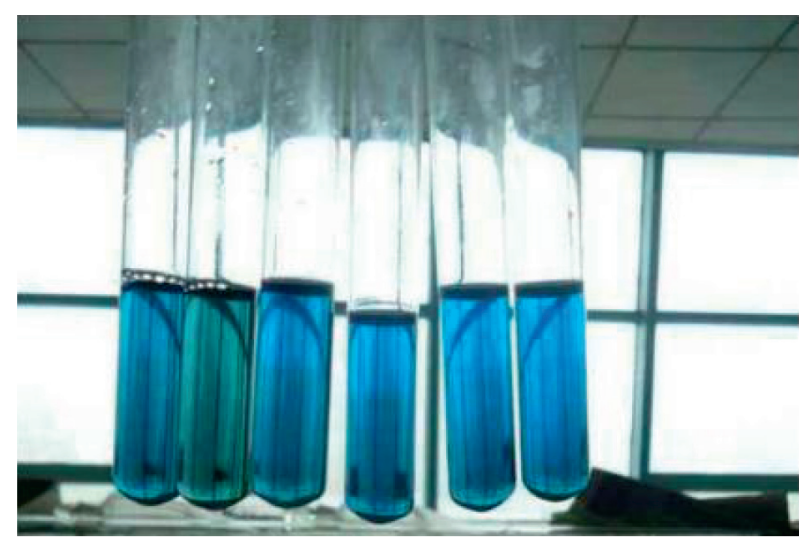

FIgURE 7: Blue solution obtained on addition of CBB.

The concentration and absorbance values obtained from the five tests of same egg white tested by a traditional spectrophotometer are shown in Table 4.

The ovalbumin mass fraction determined was tested by a traditional spectrophotometer and calculated as $0.594 \%$ $[28,29]$. Thus, the difference between the traditional spectrophotometer and smartphones value was $6.73 \%$, which is suitable for the current purpose of developing an alternative detection method.

The activity described here was carried out by 1271 students of Grades 9-11 at Yucai High School (Yinchuan, China). In this experiment, students were divided into 18 teams to test 4,500 eggs from 20 different markets in Yinchuan by a smartphone. They used a method similar to that used by researchers to measure the ovalbumin mass fraction of the egg. The ovalbumin mass fraction is listed in Table 5 .

The average ovalbumin mass fraction of local egg measured by students was $0.604 \%$.

The estimating result shows that egg white ovalbumin concentration in Yinchuan is higher than ordinary eggs. 
TABle 3: The intensities and concentrations measured by smartphone.

\begin{tabular}{lcccccccccc}
\hline Test & 1 & 2 & 3 & 4 & 5 & 6 & 7 & 8 & 9 & 10 \\
\hline Intensity (lux) & 265.3 & 265.1 & 263.9 & 266.7 & 266.6 & 265.2 & 265.9 & 266.0 & 266.6 & 265.9 \\
Concentration (g/L) & 0.46 & 0.46 & 0.48 & 0.44 & 0.44 & 0.46 & 0.45 & 0.45 & 0.44 & 0.45 \\
\hline
\end{tabular}

TABLE 4: Absorbance and concentration of same egg white tested by a traditional spectrophotometer.

\begin{tabular}{llllll}
\hline Absorbance & 0.0984 & 0.0984 & 0.0983 & 0.0990 & 0.0989 \\
\hline Concentration $(\mathrm{g} / \mathrm{L})$ & 0.4835 & 0.4833 & 0.4829 & 0.4891 & 0.4889 \\
\hline
\end{tabular}

TABle 5: Ovalbumin mass fraction measured by 18 teams of students.

\begin{tabular}{lc}
\hline Team & Ovalbumin mass fraction (\%) \\
\hline 1 & 0.582 \\
2 & 0.599 \\
3 & 0.601 \\
4 & 0.600 \\
5 & 0.589 \\
6 & 0.622 \\
7 & 0.610 \\
8 & 0.627 \\
9 & 0.621 \\
10 & 0.601 \\
11 & 0.599 \\
12 & 0.599 \\
13 & 0.597 \\
14 & 0.599 \\
15 & 0.619 \\
16 & 0.604 \\
17 & 0.607 \\
Average & 0.590 \\
\hline
\end{tabular}

\section{Conclusions}

Obviously, the rational use of new technologies is an important aspect of the problems encountered in the field of chemistry today. The development of a smartphone sensor helps laymen explore the chemistry around them. This study proves that smartphone sensors can be used in scientific experiments to obtain results with a low cost and a large degree of convenience. The estimating result shows that egg white ovalbumin concentration in eggs collected from Yinchuan is higher than that in ordinary eggs. It may also be an economic impulse for the population of less-developed areas in the Ningxia province. Smartphones can be used not only for experimental teaching in schools but also as powerful modern experimental tools in scientific experiments. However, it should be noted that this study is based on a relatively convenient sample of students from a single sector of society. Therefore, it is recommended to obtain larger and more diverse samples in future research. It will also be useful to develop a deeper understanding of the quality, not the quantity, of the technology used. We will develop more smartphone sensor experiments for measuring other ingredients in food. A further suggestion is to perform follow-up trials to determine the long-term impact of the smartphone use on people who want to learn chemistry.

\section{Data Availability}

All data used to support this study are included within the manuscript.

\section{Conflicts of Interest}

The authors declare that they have no conflicts of interest.

\section{Acknowledgments}

The authors would like to thank Ningxia University (Yinchuan, China) and Yucai High School (Yinchuan, China) for their technical and human support. This study was supported by the National Natural Science Foundation of China (No. 21261018).

\section{Supplementary Materials}

This section includes utilizing iPhone light sensors to measure egg white ovalbumin concentration in eggs. (Supplementary Materials)

\section{References}

[1] A. E. G. Falcão, R. A. Gomes, J. M. Pereira, L. F. S. Coelho, and A. C. F. Santos, "Cellular phones helping to get a clearer picture of kinematics," The Physics Teacher, vol. 47, no. 3, pp. 167-168, 2009.

[2] E. C. Hammond and M. Assefa, "Cell phones in the classroom," The Physics Teacher, vol. 45, no. 5, p. 312, 2007.

[3] S. Isaacs, N. Roberts, and G. Spencer-Smith, "Learning with mobile devices: a comparison of four mobile learning pilots in Africa," South African Journal of Education, vol. 39, no. 3, pp. 1-13, 2019.

[4] P. Guo, Z. Chai, L. Cui, G. Zhang, Z. Lu, and T. Chen, "Application of mobile APP system in university physics experiment teaching," Physics Experiment, vol. 36, no. 11, pp. 28-3, 2016, in Chinese.

[5] P. Vogt, J. Kuhn, and S. Müller, "Experiments using cell phones in physics classroom education: the computer-aided $g$ determination," The Physics Teacher, vol. 49, no. 6, pp. 383-384, 2011.

[6] P. Vogt and J. Kuhn, "Analyzing free fall with a smartphone acceleration sensor," The Physics Teacher, vol. 50, no. 3, pp. 182-183, 2012.

[7] R. Martin and S. Shin, "Photomicroscopy made easy by converting cell phones into "CellCams"” The American Biology Teacher, vol. 78, no. 1, pp. 71-75, 2016.

[8] J. Sanders and G. M. Cohen, "Observation of the optical \& chemical properties of starch granules," The American Biology Teacher, vol. 81, no. 9, pp. 644-648, 2019. 
[9] S. A. Omer and N. A Fakhre, "Simultaneous determination of ternary mixture of carboxin, chlorpyrifos, and tebuconazole residues in cabbage samples using three spectrophotometric methods," Journal of Analytical Methods in Chemistry, vol. 2020, Article ID 4912762, 16 pages, 2020.

[10] D. R. Albert, M. A. Todt, and H. F. Davis, "A low-cost quantitative absorption spectrophotometer," Journal of Chemical Education, vol. 89, no. 11, pp. 1432-1435, 2012.

[11] M. T. Koesdjojo, S. Pengpumkiat, Y. Wu et al., "Cost effective paper-based colorimetric microfluidic devices and mobile phone camera readers for the classroom," Journal of Chemical Education, vol. 92, no. 4, pp. 737-741, 2015.

[12] J. Asheim, E. V. Kvittingen, L. Kvittingen, and R. Verley, "A simple, small-scale Lego colorimeter with a light-emitting diode (LED) used as detector," Journal of Chemical Education, vol. 91, no. 7, pp. 1037-1039, 2014.

[13] T. S. Kuntzleman and E. C. Jacobson, “Teaching beer's law and absorption spectrophotometry with a smart phone: a substantially simplified protocol," Journal of Chemical Education, vol. 93, no. 7, pp. 1249-1252, 2016.

[14] G. Khalili Moghaddam and C. R. Lowe, "Smartphone-based quantitative measurements on holographic sensors," PLoS One, vol. 12, no. 11, 2017.

[15] S. R. Logan, "Beer's law: the real hazards," Journal of Chemical Education, vol. 75, no. 12, p. 1514, 1998.

[16] National Research Council, Developing Assessments for the Next Generation Science Standards, National Academies Press, Washington, D. C., USA, 2014, http://www.nextgenscience. org/.

[17] S. B. Wilson and P. Varma-Nelson, "Small groups, significant impact: a review of peer-led team learning research with implications for STEM education researchers and faculty," Journal of Chemical Education, vol. 93, no. 10, pp. 1686-1702, 2016.

[18] Y. J. Dori and M. Hameiri, "Multidimensional analysis system for quantitative chemistry problems: symbol, macro, micro, and process aspects," Journal of Research in Science Teaching, vol. 40, no. 3, pp. 278-302, 2003.

[19] A. L. Chandrasegaran, D. F. Treagust, B. G. Waldrip, and A. Chandrasegaran, "Students' dilemmas in reaction stoichiometry problem solving: deducing the limiting reagent in chemical reactions," Chemistry Education Research and Practice, vol. 10, no. 1, pp. 14-23, 2009.

[20] L. Linlin, M. Qing, and Y. Tianlin, "The yield of ovalbumin measured by using a smartphone sensor," Chinese Journal of Experimental Technology and Management, vol. 47, no. 1, pp. 69-73, 2018, in Chinese.

[21] D. Calloway, "Beer-lambert law," Journal of Chemical Education, vol. 74, no. 7, p. 744, 1997.

[22] B. Fu, "Rapid separation of egg albumin by salting out," Agricultural Science of Jiangsu, vol. 41, no. 6, pp. 229-230, 2013, in Chinese.

[23] K. Aoki and J. Hori, "Interactions of egg albumin with detergents," Journal of the American Chemical Society, vol. 81, no. 8, pp. 1885-1889, 1959.

[24] A. Ruiz-Riaguas, G. Zengin, K. I. Sinan, C. Salazar-Mendías, and E. J. Llorent-Martínez, "Phenolic profile, antioxidant activity, and enzyme inhibitory properties of limonium delicatulum (girard) kuntze and limonium quesadense erben," Journal of Chemistry, vol. 2020, pp. 1-10.

[25] Y. Mine, T. Noutomi, and N. Haga, "Emulsifying and structural properties of ovalbumin," Journal of Agricultural and Food Chemistry, vol. 39, no. 3, pp. 443-446, 1991.
[26] H. Fujita, H. Usui, K. Kurahashi, and M. Yoshikawa, "Isolation and characterization of ovokinin, a bradykinin B1 agonist peptide derived from ovalbumin," Peptides, vol. 16, no. 5, pp. 785-790, 1995.

[27] A. Dávalos, M. Miguel, B. Bartolomé, and R. López-fandiño, "Antioxidant activity of peptides derived from egg white proteins by enzymatic hydrolysis," Journal of Food Protection, vol. 67, no. 9, pp. 1939-1944, 2004.

[28] P. C. Cheung and B. M. Mehta, Handbook of Food Chemistry, pp. 331-363, Springer, Berlin, Germany, 2015.

[29] Y. F. Yano, T. Uruga, H. Tanida, Y. Terada, and H. Yamada, "Protein salting out observed at an air-water interface," The Journal of Physical Chemistry Letters, vol. 2, no. 9, pp. 995999, 2011. 